\title{
Distribution and abundance of horseshoe crabs Tachypleus gigas and Carcinoscorpius rotundicauda around the main island of Singapore
}

\author{
Lesley Cartwright-Taylor ${ }^{1, *}$, Yap Von Bing ${ }^{1,2}$, Hsu Chia Chi ${ }^{1}$, Lou Sieu Tee ${ }^{1,2}$ \\ ${ }^{1}$ Nature Society (Singapore) (NSS), 510 Geylang Road, \# 02-05 The Sunflower, Singapore 389466 \\ ${ }^{2}$ Department of Statistics and Applied Probability, National University of Singapore, Singapore 117546
}

\begin{abstract}
A survey and interviews with fishermen to determine the current spatial distribution of coastal Tachypleus gigas and mangrove Carcinoscorpius rotundicauda horseshoe crabs on the main island of Singapore indicated that there are probably no sites that support a breeding population of $T$. gigas. The only adult $T$. gigas seen were trapped in nets at 1 site, no juveniles or sub-adults were found at any site, and fishermen see this species infrequently. C. rotundicauda were more abundant, and breeding populations were found on the mudflats, fringed with mangroves. These small areas may be the last sites that support a breeding population of $C$. rotundicauda. Population density studies of mainly surface crabs on the mudflats at 1 site gave a conservative figure of $0.5 \mathrm{crabs} \mathrm{m}^{-2}$ using non-randomised, longitudinal belt-transects of $5 \times 50 \mathrm{~m}$, set from high- to low-tide zones. Smaller randomised quadrats, searched for both buried and surface crabs, gave densities of 0.57 to 0.98 individuals $\mathrm{m}^{-2}$, equivalent to a possible abundance ranging from 29925 to 51450 individuals in the accessible search area of $52500 \mathrm{~m}^{2}$. Comparisons over different months suggest that density changed little over time. Randomised quadrats and searches to depletion gave higher density figures, but they are labour intensive and difficult to set up in the terrain. Randomised, longitudinal belt-transects of $5 \times$ $50 \mathrm{~m}$ are recommended for long-term monitoring of crab density. These findings provide baseline data to monitor the population at the site and to formulate conservation strategies for the $2 \mathrm{crab}$ species.
\end{abstract}

KEY WORDS: Mangrove horseshoe crabs - Carcinoscorpius rotundicauda - Population density · Abundance $\cdot$ Transects $\cdot$ Quadrats

\section{INTRODUCTION}

Four species of horseshoe crabs exist today. Limulus polyphemus (Linnaeus, 1758) occurs along the Atlantic coast of North America, while Tachypleus tridentatus (Leach, 1819), Tachypleus gigas (Müller, 1785) and Carcinoscorpius rotundicauda (Latreille, 1802) are found in Asia, from India to Japan and south to Malaysia and Indonesia (Lee \& Morton 2005, Christianus \& Saad 2007, IUCN 2010). However, T. tridentatus is no longer found around Singapore (Davidson et al. 2008). The Asian horseshoe crab $T$. tridentatus and the coastal horseshoe crab $T$. gigas live in sandy to muddy habitats (Chatterji \& Abidi 1993, Davidson et al. 2008,
Shin et al. 2009) while the mangrove horseshoe crab C. rotundicauda inhabits muddy areas, commonly in brackish waters (Chatterji \& Abidi 1993, Ng \& Sivasothi 2002, Davidson et al. 2008). In India, some T. gigas co-exist with C. rotundicauda (Chatterji 1999, Mishra 2009). Unlike the other 3 species, C. rotundicauda does not move out to sea with the receding tide. Instead, adults can be found buried from 2 to $3 \mathrm{~cm}$ deep in the wet mud, while sub-adults and juveniles remain on the surface.

In higher latitudes, horseshoe crabs in Asia, like their counterparts in the United States, hibernate in deeper waters during winter months and migrate to spawning beaches in spring and summer (Sekiguchi 1988, Chiu 
\& Morton 2003, Shin et al. 2009), but in tropical latitudes, where the water temperature varies little, there is no such seasonal behaviour (Cartwright-Taylor et al. 2009). Spawning of Tachypleus gigas and Carcinoscorpius rotundicauda has been reported during spring tides throughout the year in India (Chatterji et al. 1992, Chatterji \& Abidi 1993) and Malaysia (A. Christianus pers. comm.), and is thought to occur in Singapore at the same times (Mikkelsen 1988, Davidson et al. 2008), but has not been reported there yet.

All 4 species of horseshoe crab are classified as either near threatened or data deficient (IUCN 2010). Habitats throughout Asia are diminishing, and evidence from studies and local fishermen suggests that all species, once commonly found, are in decline. For example, in India, spawning activity has been adversely affected by the degradation and destruction of spawning beaches of both Carcinoscorpius rotundicauda and Tachypleus gigas (Mishra 2009). In Hong Kong, juvenile densities have been declining for some years (Morton 1999, Chiu \& Morton 2003), and juveniles are found in fewer locations (Shin et al. 2009). T. gigas is now thought to be extirpated locally around Hong Kong (Lee \& Morton 2005). A favoured site for C. rotundicauda research off the coast of Malaysia was recently lost to land reclamation (A. Christianus pers. comm.).

In addition to loss of habitat, entrapment in fishing nets in coastal waters and commercial harvest for food remain threats for crab populations. In Hong Kong Tachypleus tridentatus is sold in restaurants (Shin et al. 2009), and in Thailand and Malaysia all 3 Asian species are consumed as an exotic delicacy (Christianus \& Saad 2007). On the east coast of Malaysia at Sedeli Kechil and in Johor, hundreds of horseshoe crabs, mainly T. gigas, are harvested every week and exported mainly to Thailand (A. Christianus pers. comm., S. Supari pers. comm.). Horseshoe crabs in this region are not regulated or managed, so this trade is likely to continue until they are extirpated. In India, even at sites where horseshoe crabs are protected, illegal collection of Carcinoscorpius rotundicauda and T. gigas for pharmaceutical research continues and is increasing (Patti 2008).

In Singapore, only Tachypleus gigas and Carcinoscorpius rotundicauda remain, and the former has now diminished to critically low numbers (Davidson et al. 2008). Anecdotal evidence from fishermen and local people indicates that these species were abundant on the beaches of Singapore's main island in the 1950s and 1960s, and the larger species, T. gigas, was commonly sold in markets for consumption. Habitat loss has been the main cause of the decline of both species in Singapore, as areas of coastal land have been used for development, land reclamation and coastal devel- opment (Davidson et al. 2008). Few natural sandy beaches remain, and infrequent sightings of $T$. gigas reported on web sites (e.g. www.wildsingapore.com/ wildfacts/arthropoda/limulidae/tachypleus1.htm, accessed on 30 October 2010) or blogs suggest that this species is now rare on the main island. Similarly, mangrove forest area, covering about $70 \mathrm{~km}^{2}$ on the main island of Singapore in 1819, is now down to $6.59 \mathrm{~km}^{2}$, most of which is restricted to the north-west of the main island (Yee et al. 2010), where a small area of forest and a fringe of mangroves along the shore remain. Mangroves act as nursery areas for many marine species including C. rotundicauda (Chatterji \& Abidi 1993, Ng \& Sivasothi 2002), but Singapore has no laws that protect marine ecosystems, and crabs collected for medical research (Ding et al. 2005) or to stock the Singapore Zoo Fragile Forest display (J. Kee pers. comm.).

Based on loss of habitat Carcinoscorpius rotundicauda and Tachypleus gigas are now classified in Singapore as vulnerable and endangered, respectively, with both species considered at high risk of extinction (Davidson et al. 2008). Distribution surveys and quantitative data are urgently needed to confirm the conservation status of these species, to monitor emerging threats to the remaining horseshoe crab population in Singapore, and to justify actions to protect these species.

One goal of our study was to collect information on the current population distribution of both Tachypleus gigas and Carcinoscorpius rotundicauda on the main island of Singapore. In March 2009 an island-wide survey of the remaining likely habitat sites was conducted by volunteers of the Nature Society (Singapore) (NSS). At the same time fishermen at the sites were questioned about how often they caught or saw horseshoe crabs in order to collect information on where or when horseshoe crabs may still be found.

A second goal of the study was to gather baseline data on the density of a known population of Carcinoscorpius rotundicauda at the Mandai mudflats, Kranji, on the north shore of Singapore. Between October 2007 and June 2009, figures were collected in different months to detect any periodic changes in density. With these baseline data the population can be monitored over time.

A third goal of the study was to test methods for conducting density counts of surface and buried Carcinoscorpius rotundicauda at the Mandai mudflats, which present many sampling challenges. Walking over the soft mud is difficult, thunderstorms are common, search times are limited to the low tide period, and the ambient temperature and humidity are high. Visibility of the water is too poor for using snorkels or view boxes as is done for species on sand (Carmichael et al. 2003), and the nature of the mud and accumulated debris preclude collection with rakes. Collection of crabs can 
only be done by hand using visual searches of the mud surface and probing for buried crabs, a labour-intensive search method. Methods for estimating horseshoe crab densities that can be replicated easily and are practical under these conditions over difficult terrain are needed. In our study, 2 methods were used, and density figures are presented.

\section{MATERIALS AND METHODS}

Experienced horseshoe crab volunteers assisted with all activities in the present study. They had been trained in horseshoe crab biology, identification, search methods, data collection and recording before participating in searches or surveys, and they were closely supervised during the activities.

Island-wide survey. An island-wide survey of likely horseshoe crab habitats was conducted to determine the spatial distribution of Tachypleus gigas and Carcinoscorpius rotundicauda around Singapore's main island. As far as possible we followed the stages of the horseshoe crab survey design described by Smith et al. (2002).

First stage: We considered likely and accessible habitats of both species, Carcinoscorpius rotundicauda and Tachypleus gigas. Seven accessible sites around Singapore's main island, where development and land reclamation have not destroyed the natural topography of the shore, were selected for the survey in addition to the Mandai mudflats, where a population of $C$. rotundicauda exists. Without records of spawning or nursery beaches, site selection was based on habitat type and anecdotal reports of horseshoe crab sightings.

Sites around the north and north-west of the island (Fig. 1) were selected because these are the remaining mangrove-fringed shores of the island. One site in the south adjacent to Pandan Reservoir was selected because it is also a mangrove-fringed tidal mudflat open to the sea that is a likely habitat for Carcinoscorpius rotundicauda. Sites in the north-east were chosen because these are the only remaining natural sandy beaches where horseshoe crabs were commonly seen during the 1950s and 1960s. These are the sites most likely to support a population of Tachypleus gigas around the main island. The entire south and east is now reclaimed land, with steeply sloping, man-made beaches.

Second stage: A suitable date for the survey was determined. Horseshoe crabs in tropical Asia are thought to spawn monthly at the high spring tide period, particularly during the day (Mikkelsen 1988, Chatterji et al. 1992). The spring tide period was chosen to give the best chance of sighting individuals on the largest area of the shore following the receding tide. The survey was conducted at all beaches on the same afternoon in March 2009, within 3 d of the full moon.

Third stage: This stage involved searching the selected beaches; before initiation, an instruction briefing on the search method was held with all participants. Teams of 5 to 15 volunteers, depending on the size of the beach, started the search at their allocated site halfway through ebb tide. The volunteers spread out and walked abreast of one another in a line from one end of the beach to the other covering the entire beach area. Those searching the mudflats probed for buried crabs, while those searching the sandy beaches included the shallow waters of the receding tide in their search. None of the beaches is extensive, so the whole area of all but one of the sites could be searched within $\sim 2 \mathrm{~h}$. The exception was the mudflat in the south near Pandan Reservoir, where the search was limited in time and area because the mud was deep and dangerous.

All horseshoe crabs were counted, and species and gender were recorded. Quadrat counts (as described by Smith et al. 2002), were not planned during the survey, because, with the exception of the known population at Mandai mudflats, there was no certainty that horseshoe crabs would be found. Density findings from Mandai are given below. Density counts elsewhere were done at a later date if warranted by the numbers found.

Fishermen's questionnaire. During the survey, a standard questionnaire was used to interview fishermen at the sites about sightings and catches of horseshoe crabs from in-shore waters, to provide information on when and where horseshoe crabs may be found.

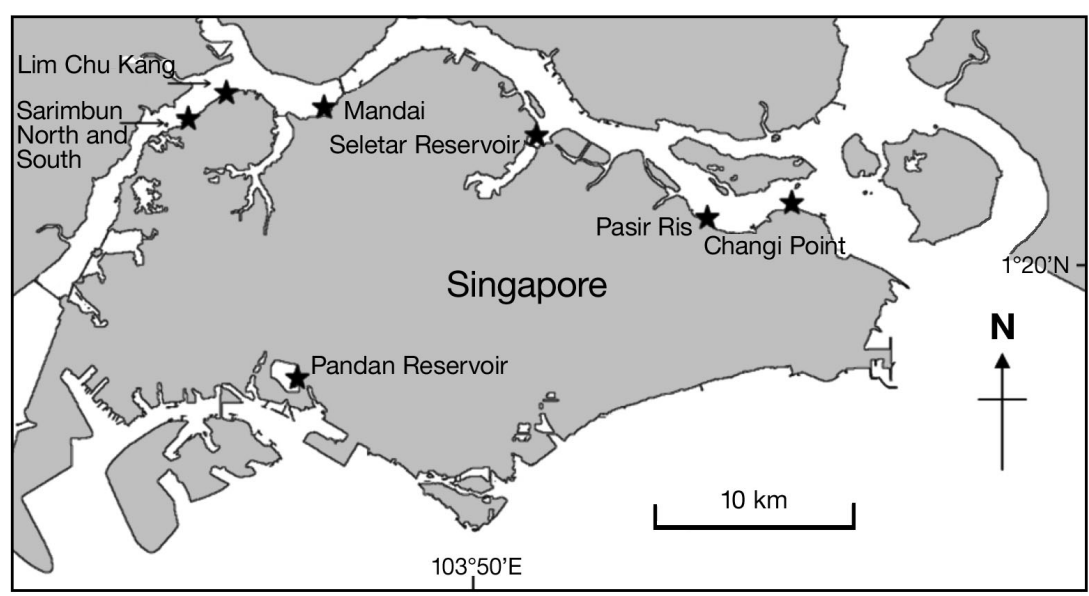

Fig. 1. Sites of the island-wide survey of horseshoe crabs Carcinoscorpius rotundicauda on Singapore's main island in March 2009 
These fishermen use small boats and fine nets to fish for their own consumption and recreation in local, inshore waters, and are the people most likely to see horseshoe crabs as by-catch or because they frequent the beaches. The volunteers used a prepared questionnaire of 8 questions with photographs of the 2 horseshoe crab species for illustration. The aim was to determine from the fishermen where and when horseshoe crabs are seen, in order to identify any other possible sites that might support a population of horseshoe crabs. Questions included whether the fishermen had ever seen or caught horseshoe crabs, if so when (time of year, time of day, phase of the tide), where and how far from shore, in what numbers they had been seen, and when their last sighting had occurred. Fishermen were also asked if they knew there were 2 species of horseshoe crabs around the island, differentiated by size and tail shape, and if they thought horseshoe crabs were edible.

Population density studies at Mandai mudflats. One of the survey sites, the Mandai mudflats, is known to support a population of Carcinoscorpius rotundicauda year-round, and NSS volunteers visit the site regularly to rescue horseshoe crabs entangled in fishing nets. At this 1 site, density data were collected using 2 different methods 6 times over a period of 18 mo from October 2007 to June 2009, including during the island-wide survey.

Study site: The study site and resident horseshoe crab population structure have been described in detail (Cartwright-Taylor et al. 2009). The site is on the north coast of the main island of Singapore at Kranji $\left(1^{\circ} 26^{\prime} \mathrm{N}, 103^{\circ} 45^{\prime} \mathrm{E}\right)$, the largest area of mudflats remaining in Singapore. At low tide the mudflats extend over an area of $\sim 450000 \mathrm{~m}^{2}$, but the search area of interest that included all transects and quadrats was $\sim 9000 \mathrm{~m}^{2}$.

The tidal range is $\sim 3.3 \mathrm{~m}$, and the mudflats exposed during the spring tide extend $\sim 200 \mathrm{~m}$ to the low-tide mark. There is a narrow fringe of mangroves near the shore line, the mud is at least ankle deep, and part of the shore is bounded by a sea wall. The water temperature ranges from $\sim 26$ to $31^{\circ} \mathrm{C}$ throughout the year (Cartwright-Taylor 2008), and the salinity in the strait typically exhibits 2 high levels ( 20 to 26) in March/ April and October/November, and 2 low levels ( 15 to 20) in January and June/July (Ng \& Sivasothi 2002, Cartwright-Taylor 2008), depending on the state of the tide, weather and terrestrial runoff. Mangrove horseshoe crabs can be found scattered year round throughout the entire exposed intertidal zone (CartwrightTaylor 2008).

Search methods: Visual searches were made during spring tides when the mudflats were exposed. Smaller crabs can be seen on the surface of the mud, while adults may be partially or completely buried and can be detected by probing the top 6 to $8 \mathrm{~cm}$ of the mud. This method does not assess activity of the horseshoe crabs under water or include individuals in deeper water, but is the only way the mangrove horseshoe crabs could be found on the mudflats.

Belt transects: The first sampling method for population density calculations used non-randomised belt transects in October 2007 and March 2008, during a change in the monsoon, when the prevailing wind changed direction from south-west (June to October) to north-east (December to March). This was to determine if there were any differences in density that would suggest periodic migration to or from the site.

Four parallel, continuous-belt transects of $5 \times 50 \mathrm{~m}$ (250 $\mathrm{m}^{2}$ each) running in a seaward direction (Chalmers \& Parker 1989) were marked out approximately perpendicular to the shore and between 45 and $75 \mathrm{~m}$ apart, spread over the accessible, exposed search area. The transects were set up in the same place each visit, using compass bearings and permanent structures as reference points, and were demarcated with poles and string. The distribution of the horseshoe crabs across the mudflats was not known at the outset, so the positions of the transects were not chosen with any reference to the densities of horseshoe crabs. A team of 3 trained and experienced volunteers was allocated to each transect. The teams made visual searches of the mud surface. Starting at the high-tide zone and working seaward, the volunteers collected all crabs seen in the given transect over a standard period of time $(1.5 \mathrm{~h})$ that was adequate for the volunteers to reach the end of the transect. Population density was expressed as number of horseshoe crabs per square metre. Using the same transect areas and search time, the data from each sampling exercise were compared over time.

Randomised quadrats: The second sampling method at the Mandai mudflats made use of a simple random sampling design, conducted during the spring tide of 4 months, January, February, March and June 2009. Searches along the belt transects could not reveal all buried crabs because the area in each transect was too great to conduct such thorough searches in the time available, so searches to include buried crabs were conducted in smaller randomised quadrats selected over the entire area between 2 of the belt transects (T1 and T2; Fig. 2).

Geo-referencing software including Google Earth, GE Path (Sgrillo 2009) and a GPS machine (Garmin GPS 72) were used to locate the quadrat coordinates. First, using Google Earth, the boundary of the mudflat area between the first 2 transects (T1 and T2) was drawn with GE Path. Then the R program (R Development Core Team 2009) was used to generate a series of 
random numbers, each incorporating the latitude and longitude of the coordinates. At the sampling site, the GPS was used to trace these coordinates and mark the corners of the area with a red pole. This area was divided into quadrats of equal size and a subset of these quadrats was selected randomly without replacement. Three trained volunteers were assigned to each quadrat, and searches were carried out as far as possible to depletion by collecting horseshoe crabs on the mud surface and by probing in the mud with fingers or small hand-held gardening forks to a depth of $\sim 6$ to $8 \mathrm{~cm}$ to detect buried individuals.

In January 2009 an area of $50 \times 50 \mathrm{~m}$ (equivalent to $2500 \mathrm{~m}^{2}$ ) between the belt transects, T1 and T2, was defined as the area of interest (Fig. 2). This area was then divided into 25 strips of $50 \times 2 \mathrm{~m}$, aligned almost perpendicular to shore, from the high- to the low-tide zone. Two of these strips $(n=2)$ were selected at random without replacement, and were searched to depletion. Initially, 4 random strips were to be searched, but in practice, they were too large for $>2$ strips to be searched in the time available over the difficult terrain, so in February 2009, for the second sampling, the randomised search sections were reduced in size and a larger sample size was used to reduce the sampling variability while keeping the area searched the same. This time the same area at the same site position $\left(2500 \mathrm{~m}^{2}\right)$ as in January was divided into 125 rectangular quadrats of $10 \times 2 \mathrm{~m}$ each. Of these, 10 quadrats were randomly selected and searched without replacement (Fig. 2). The data from 1 of the quadrats were lost, leaving data from 9 quadrats.

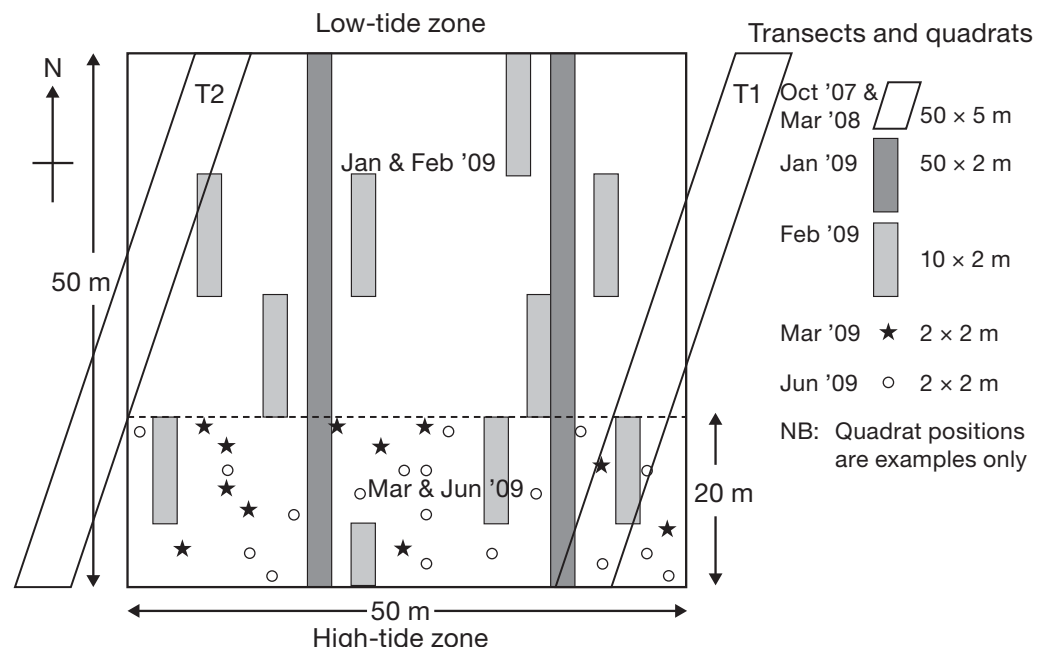

Fig. 2. Density surveys for Carcinoscorpius rotundicauda at Mandai mudflats, Kranji. Two transects (T1 and T2) were sampled in both 2007 and 2008 (2 additional transects outside the illustrated area are not shown). Two large and 10 medium quadrats were sampled in January and February 2009, respectively. In March and June 2009, the search area was reduced to $20 \times 50 \mathrm{~m}$ (below dashed line), and 25 small quadrats were searched in each month. Transects were searched for surface crabs only, while quadrats were also probed for buried crabs
In March and June 2009, for the third and fourth samplings, the same site and positions as the ones in February 2009 were used, but the area size was reduced to $20 \mathrm{~m}$ towards the sea instead of $50 \mathrm{~m}$, but remained $50 \mathrm{~m}$ along the shore (equivalent to $1000 \mathrm{~m}^{2}$ ), as shown in Fig. 2. The size of the quadrats within this area was also reduced. This time the area was divided into 250 quadrats of $2 \times 2 \mathrm{~m}\left(4 \mathrm{~m}^{2}\right)$, and 25 quadrats were selected randomly for March and again for June without replacement. This was to determine the trade-off between the work involved and the precision gained with larger sample sizes. These quadrats were each searched to depletion as before. In each case, 3 volunteers at each quadrat used the same search technique. The search area and the quadrats are shown in Fig. 2 for January, February, March and June 2009.

Before any tests were conducted, normality of data and homogeneity of variances were checked by plotting a histogram with a normal curve imposed on it. Statistical analysis was performed using Microsoft Excel and the R Project for Statistical Computing (Version 2.7.2).

\section{RESULTS}

\section{Island-wide survey}

The only live Tachypleus gigas seen on the main island were 6 adult females at Changi Point that had become caught up in a fisherman's net (Table 1). Three dead adults were found at Lower Seletar where the substrate is a mixture of sand and mud, and 2 other dead adults were found in areas that are predominantly mangrove areas inhabited by Carcinoscorpius rotundicauda, suggesting that these 2 species may co-habit. This is supported by both species, either alive or dead, being seen at 4 sites. No juvenile $T$. gigas were seen.

Mangrove horseshoe crabs Carcinoscorpius rotundicauda were found at the 5 mangrove sites sampled, but the area including 4 of these sitesMandai, Lim Chu Kang and Sarimbun (North and South) - is contiguous and can be considered 1 habitat type. These were the only sites where juveniles as well as adults were found. Dead horseshoe crabs were also found at Changi Point and Pasir Ris, habitats more typical of Tachypleus gigas, again suggesting some co-existence. At Pandan Reservoir, also an area of 
Table 1. Site characteristics and number of adult and juvenile (juv; in brackets) Carcinoscorpius rotundicauda and Tachypleus gigas found at each location surveyed on the main island of Singapore. NA: not available

\begin{tabular}{|c|c|c|c|c|c|c|}
\hline \multirow[t]{2}{*}{ Site } & \multirow[t]{2}{*}{ Habitat type } & \multirow{2}{*}{$\begin{array}{l}\text { Beach width } \\
\text { (m) }\end{array}$} & \multicolumn{2}{|c|}{ C. rotundicauda } & \multicolumn{2}{|c|}{ T. gigas } \\
\hline & & & Live & Dead & Live & Dead \\
\hline Changi Point & Sandy beach & 200 & 1 & 1 & $6^{\mathrm{a}}$ & 2 \\
\hline Pasir Ris & Sandy beach & 150 & 0 & 1 & 0 & 0 \\
\hline Lower Seletar & Sand and mud & NA & 2 & 6 & 0 & 3 \\
\hline Mandai (near Kranji) & Mangrove & 100 & 60 (44 juv) & 2 & 0 & 0 \\
\hline Lim Chu Kang & Mangrove & 330 & 57 (6 juv) & 3 & 0 & 1 \\
\hline Sarimbun North & Mangrove & 350 & 39 (31 juv) & 0 & 0 & 0 \\
\hline Sarimbun South & Mangrove & 300 & 9 (8 juv) & 0 & 0 & 1 \\
\hline Pandan Reservoir & Mangrove & 500 & 4 & 1 & 0 & 0 \\
\hline${ }^{\mathrm{a}}$ Adult females in nets & & & & & & \\
\hline
\end{tabular}

mud with a mangrove fringe, 4 live adult $C$. rotundicauda were found, but the search was abandoned prematurely because it was too dangerous to continue in the deep mud. At none of the sites surveyed, except Mandai, were sufficient numbers of crabs found to warrant more detailed counts.

\section{Fishermen's questionnaire}

Using prepared questionnaires, volunteers asked fishermen present at the survey sites about their experiences with catching horseshoe crabs as by-catch. In total, 22 questionnaires were completed, with 9 from 1 site and up to 4 at other sites. However, not all questions were answered by all those questioned. The fishermen were asked about both Carcinoscorpius rotundicauda and Tachypleus gigas, but none of them understood that these are separate species. Thus, many of the answers they gave applied to horseshoe crabs in general.

Of the 22 fishermen, 19 (86\%) had seen horseshoe crabs and knew what they were, but none of them was aware that horseshoe crabs are endangered or vulnerable. Horseshoe crabs were more commonly seen on the beach $(63 \%)$ or among mangroves ( $41 \%)$ than in deeper waters out at sea $(27 \%)$ or within $100 \mathrm{~m}$ of shore $(41 \%)$. While $45 \%$ said they had seen the smaller species within the previous $3 \mathrm{mo}$, only $18 \%$ said they had seen the larger species, T. gigas, that recently. None had seen horseshoe crabs at neap tides, but $77 \%$ mentioned sightings throughout the tidal cycle and in all other tidal periods. These local fishermen use small boats and fish inshore. Several fishermen commented about always observing horseshoe crabs in pairs, and more often in some months than in others, with January to March and the mid-year period most commonly cited $(27 \%)$. Horseshoe crabs are caught in nets as bycatch, but most fishermen typically throw them back into the sea. However, one reported that he keeps the large ones to eat. Others said that the eggs can be eaten, but, in general, there seemed to be little consumer demand for horseshoe crabs in Singapore.

Differentiating the species on size alone, both species were reported at all sites, with the exception of Carcinoscorpius rotundicauda being absent at Pasir Ris, a sandy beach, and Tachypleus gigas being absent at Lim Chu Kang, a muddy beach with a mangrove fringe. Unexpectedly, T. gigas was also reported from areas that are typically inhabited by C. rotundicauda, such as in Sarimbun, although it is not seen as commonly as the latter, and $C$. rotundicauda was reported at a site typically favoured by $T$. gigas, suggesting that the 2 species co-exist.

\section{Abundance and population density at Mandai mudflats}

Belt transect method: comparisons between October 2007 and March 2008

Although the densities varied from transect to transect and over time, the mean density of each of the 4 transects was 0.50 crabs m$^{-2}$ (Table 2), suggesting that the transition in the monsoon has no marked effect on population density.

Table 2. Carcinoscorpius rotundicauda. Density of horseshoe crabs along four $250 \mathrm{~m}^{2}$ belt transects at Mandai mudflats, Kranji, in October 2007 and March 2008

\begin{tabular}{|c|c|c|c|c|}
\hline \multirow{2}{*}{ Transect } & \multicolumn{2}{|c|}{$\longrightarrow$ Oct $2007-$} & \multicolumn{2}{|c|}{ - Mar 2008} \\
\hline & Abundance & $\begin{array}{c}\text { Density } \\
\left(\text { no. } \mathrm{m}^{-2}\right)\end{array}$ & Abundanc & $\begin{array}{l}\text { Density } \\
\left(\text { no. } \mathrm{m}^{-2}\right)\end{array}$ \\
\hline 1 & 123 & 0.49 & 206 & 0.82 \\
\hline 2 & 241 & 0.96 & 92 & 0.37 \\
\hline 3 & 79 & 0.32 & 117 & 0.47 \\
\hline 4 & 57 & 0.23 & 85 & 0.34 \\
\hline Total & 500 & 0.50 & 500 & 0.50 \\
\hline
\end{tabular}


These are probably minimum figures, and more individuals could have been found had the search included thorough probing of the mud for buried crabs. From a comparison of these figures using 2-sample $t$-tests, we conclude that the overall density in the 4 transects probably did not change much between October 2007 and March 2008. While the assumption that data were randomly sampled was violated in the 2007 and 2008 transect samplings, subsequent data (2009) support our initial finding for 2007 and 2008 that horseshoe crab density did not change over time $(p=0.7)$. To facilitate a comparison with later surveys, we looked at the first 2 transects, for which the average density changed from $0.73 \mathrm{crabs} \mathrm{m}^{-2}$ in October 2007 to

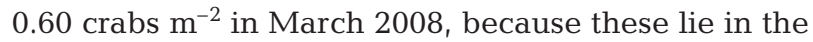
same area of interest as the later surveys (Table 3).

\section{Randomised surveys}

The densities for all randomised surveys are presented (Table 3), together with the densities for October 2007 and March 2008 averaged from T1 and T2 for comparison, because these 2 transects overlapped the area of the randomised surveys. The mean $( \pm$ SE) estimated densities in January and February were consis-

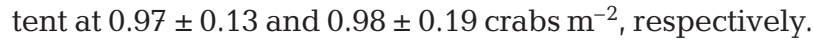
The densities in March and June, from smaller quadrats than in January and February, were slightly lower at $0.60 \pm 0.09$ and $0.57 \pm 0.08$ crabs $^{-2}$, respectively.

None of the comparisons of crab density estimates from the surveys (2007 to 2009) was significant (2-sample $t$-tests, all $\mathrm{p} \geq 0.1$ ).

Abundance in the accessible, exposed mudflats

The accessible search area of the mudflats at the site at low tide is $\sim 52500 \mathrm{~m}^{2}(150 \times 350 \mathrm{~m})$, without including adjacent areas in the mangrove forest to the east

Table 3. Summary of Carcinoscorpius rotundicauda density estimates from the randomised surveys. T1 and T2: Transects 1 and 2; NA: not availabe

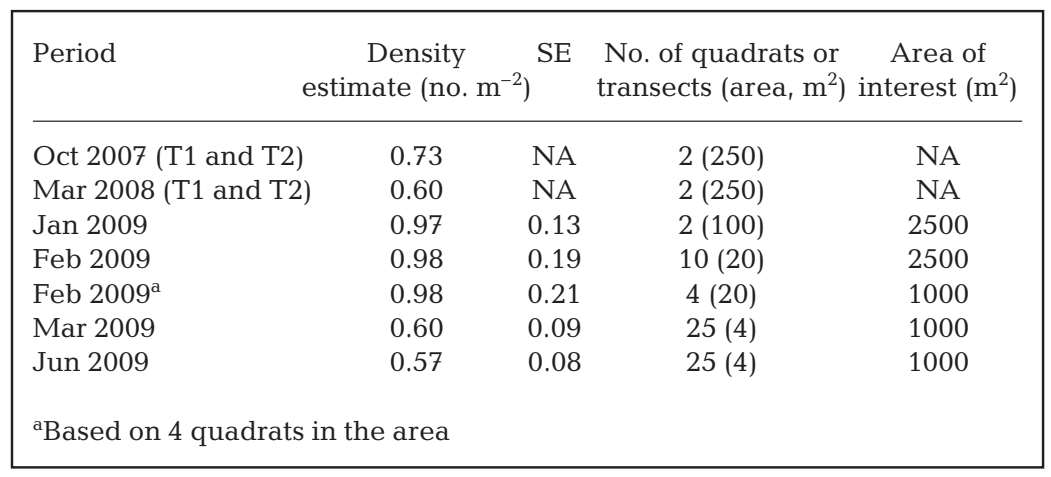

$(1500 \mathrm{~m})$ or beyond the concrete retaining sea wall to a stream in the west $(1500 \mathrm{~m})$. If the lowest and highest densities observed during 2009 (0.57 and $\left.0.98 \mathrm{~m}^{-2}\right)$ are used as the upper and lower levels, an abundance of between 29925 and 51450 individuals can be inferred in the accessible search area on the exposed mudflats alone. If the adjacent areas are also included, the site area becomes $\sim 3000 \times 150 \mathrm{~m}\left(450000 \mathrm{~m}^{2}\right)$, with a possible abundance of 256500 to 441000 crabs.

\section{DISCUSSION}

\section{Island-wide survey}

\section{Tachypleus gigas}

Our 2009 survey of the distribution of horseshoe crabs around the shores of the main island of Singapore suggests that the situation for Tachypleus gigas is critical. Unfortunately, there are no recorded historical data on horseshoe crab distribution and abundance in any habitat in Singapore, only anecdotal evidence that the species was once abundant. However, the data from the present study suggest that $T$. gigas may no longer be breeding around the main island. No juveniles or sub-adults were seen that would suggest sustainable communities or a spawning area at the sites surveyed, yet Changi Point, in particular, was an area where fishermen claim to have seen many horseshoe crabs in earlier years. T. gigas is occasionally seen on Pulau Ubin, an island just off Changi Point, and the few that were seen in nets at Changi Point may suggest that T. gigas can still be found around some of the off-shore islands that have remained untouched by land reclamation. Isolated $T$. gigas are occasionally seen at Changi Point (T. Y. Goh pers. comm.), but no nesting activity has been reported here or on any other beach on the main island so that survival of this species is of major concern. It is uncertain where breeding sites may still exist; the remaining sandy beaches are popular recreational areas and are regularly visited by nature enthusiasts and any nesting activity would most likely have been reported.

The findings from the survey and from fishermen's reports support the current conservation status of Tachypleus gigas in Singpore as endangered (Davidson et al. 2008). Although there is no large commercial market for horseshoe crabs in Singapore, the paucity of $T$. gigas, in particular, may in part be due to the significant export 
from places in nearby southeast mainland Malaysia to Thailand and Vietnam. However, until horseshoe crabs are protected in both Singapore and Malaysia, the trade will continue to affect population numbers.

\section{Carcinoscorpius rotundicauda}

The island-wide survey suggests that breeding populations of this species are probably restricted to the north-west of the island in the Strait of Johor, supporting the conservation classification of 'vulnerable' for this species (Davidson et al. 2008). Sarimbun North and South are areas contiguous with the Mandai mudflats. Therefore, the sea bordered by the Singapore coast stretching from just east of the Mandai mudflats through the Sungei Buloh Wetlands Reserve to the Sarimbun area, with the corresponding Johor coast across the Strait in Malaysia may be an area of significance in the conservation management of this species and should be considered in any future management plan of the area.

With the exception of a small mudflat near a reservoir on the south and mudflats along the north-west coast, mangrove forest or fringes that used to support Carcinoscorpius rotundicauda have disappeared. Although the mangrove horseshoe crabs at the Mandai mudflats are still abundant, the remaining area of mangrove forest or fringe along the north-west shoreline is small $\left(\sim 1.3 \mathrm{~km}^{2}\right.$ compared to $710.3 \mathrm{~km}^{2}$, the total area of Singapore), and $<1.9 \%$ of the area it once covered on the main island (Yee et al. 2010). The Mandai mudflats, together with the north-west shore, probably represent the last site on the main island that is known to support a thriving population of $C$. rotundicauda. Although this is now the largest remaining mudflat in Singapore, the area is not large and the habitat is unprotected. The NSS has been in talks with the Singapore government to bring the site and adjacent mangrove forest under the protection of the wetland reserve and to protect the whole area under the Ramsar Convention (H. C. Ho pers. comm.). The society is also pressing for the introduction of legal measures to prevent the use of and the discarding of fishing nets in inland water bodies and coastal waters to avoid entrapment of horseshoe crabs (http:// conservationsingapore.nss.org.sg/ [accessed on 25 October 2010]). Across the Strait of Johor, Malaysia is implementing plans to develop the coastline of South Johor (www.iskandarmalaysia.com.my/overalldevelopment-plan-map [accessed on 4 May 2010]). This will lead to changes in land use on the Malaysian side of the strait and accelerate conversion of natural resource areas into urban land, with detrimental effects on the habitats along both sides of the strait.

\section{Co-existence of both species}

Interestingly, since live individuals of both species were seen at 1 site and dead individuals of both species were seen at other sites, there may be some overlap in the distribution of the 2 species, with coexistence at some sites. Since the survey, one of the authors (L.C.T.) has seen 2 live adult Tachypleus gigas in a catch of Carcinoscorpius rotundicauda at Lim Chu Kang, which is a typical C. rotundicauda site, and a dead T. gigas in a net at the Mandai mudflats. Although uncommon, such co-existence has also been reported from the east coast of India, where T. gigas was more numerous in conditions of high salinity but as the salinity decreased at the site, C. rotundicauda became more numerous (Chatterji 1999, Mishra 2009). Co-existence may occur in the Strait of Johor, an estuary where salinities also vary during the year depending upon the state of the tide, weather and terrestrial runoff. These monthly fluctuations might provide suitable conditions for both species. Such co-existence may be more apparent if the numbers of $T$. gigas were not quite so low.

\section{Mandai mudflat density}

Population density figures for C. rotundicauda at the Mandai mudflats varied from 0.50 to 0.98 individuals $\mathrm{m}^{-2}$, depending on the method used and the area surveyed. Using the same transects and procedures, there was no evidence of any significant change in density between October 2007 and the following March, or from early in the year to mid-year, suggesting that density does not change greatly with changes in the monsoon or from month to month. The comparisons with the 2 lowest p-values of 0.1 , January 2009 compared with March 2009 and with June 2009, might suggest some evidence that there is a small change in density. In addition, the density data show a decreasing trend that could reflect the effects of environmental change or simply the difference in location, but there is no satisfactory method to isolate these 2 factors. Electronic tagging methods would clarify whether any periodic horseshoe crab movement to or from the site occurs, and such studies are now in progress.

One of the objectives of our studies was to determine optimum methods of measuring density for long-term monitoring that would be both practical in the difficult terrain and statistically robust and reproducible. The method using randomised quadrats with intensive probing for buried crabs entailed much greater difficulties in practice and took longer to set up than the simpler belt transect method, but provided more accurate figures. Although the comparison of density figures be- 
tween the belt transects and the quadrats may be confounded by time, the study served to demonstrate the practical difficulties of setting up randomised quadrats. Moreover, randomised quadrats would inevitably be at variable distances from shore in successive surveys, necessitating accurate placement of the quadrats each time. Therefore, for frequent density studies and longterm monitoring, we recommend using the same belt transects down the length of the beach, but randomising the transects the first time within a predetermined area of the mudflat. Thus, all transects would have the same placement within the intertidal zone, eliminating the variable distance from the shore. Such randomised belt transects would be quick and easy to set up. This, coupled with increased probing of the mud, would provide more accurate and comparable figures that would be statistically robust.

The present study has established that there is still a thriving population of Carcinoscorpius rotundicauda at the Mandai mudflats at Kranji, calculated to range from 29925 to 51450 individuals in the mudflat search area alone. The habitat continues along the shore and across to the opposite shore of the strait, where mangrove horseshoe crabs may be found. Thus, this abundance range is likely to be an underestimate, as there will be additional individuals in the contiguous habitat and probably also in the strait below the low-tide mark in the deeper waters of the Strait of Johor. Very small juveniles and sub-adults can be seen on the Mandai mudflats in all months (Cartwright-Taylor et al. 2009), so it is likely that the remaining mangroves to the east of the site and beyond the wetlands reserve to the west act as nursery areas for the population of horseshoe crabs along the entire coast, extending west along a restricted stretch of undeveloped shore. Outside these boundaries, the shoreline is highly developed with reclaimed land without beaches or with small manmade beaches that are likely to be too steeply shelved for horseshoe crabs.

In comparison with surveys of horseshoe crab species in other parts of the Asian Pacific, the density of Carcinoscorpius rotundicauda at this small site is high. In Hong Kong the highest density of Tachypleus tridentatus was 0.31 individuals per $100 \mathrm{~m}^{2}$, while C. rotundicauda was even more scarce (Shin et al. 2009). In their survey of 17 beaches, Shin et al. (2009) could not find any $C$. rotundicauda using the transect method, while only 30 juveniles were found in summer and 4 in winter by 2 people using a $3 \mathrm{~h}$ walk-through method over an area of $1280 \mathrm{~m}^{2}$ at each site. A survey of T. tridentatus at a nursery beach in the Philippines reported 1.47 individuals $100 \mathrm{~m}^{-2}$ (Almendral \& Schoppe 2005). At a site in South China, Beibu Gulf, the mean density of T. tridentatus over 6 transects was 1.02 juveniles $100 \mathrm{~m}^{-2}$, with a maximum mean density of 2.43 juve- niles $100 \mathrm{~m}^{-2}$ (Hu et al. 2009). A study of T. gigas in Orissa (Chatterji et al. 1992) conducted more than $20 \mathrm{yr}$ ago, between 1985 and 1987, recorded a maximum in any 1 mo of 33 individuals along a $200 \mathrm{~m}$ transect, and actual densities now may be even lower as a result of ongoing poaching (Patti 2008).

The loss of horseshoe crabs from Singapore's main island appears to be following the same pattern of decline as that reported elsewhere in the Asian Pacific region. In Hong Kong, a sharp decline in horseshoe crab populations of $>90 \%$ occurred in the 2 yr prior to 2009 (Shin et al. 2009). Previously, sightings of Tachypleus gigas have been reported from many shores along the Asian Pacific coast (Mikkelsen 1988), but now only $T$. tridentatus and Carcinoscorpius rotundicauda are found in Hong Kong, and in declining numbers (Chiu and Morton 1999, 2003, Shin et al. 2009); at the same time, horseshoe crab populations are diminishing in other countries including Taiwan (Chen et al. 2004), Japan (Itow 1993) and Malaysia (Christianus \& Saad 2007). Indeed, a warning of possible extinction unless conservation measures are taken was issued 2 decades ago (Earle 1991). Protection of even small or isolated sites such as those in Hong Kong (Shin et al. 2009) and in Singapore by designating them as 'Sites of Special Scientific Interest' or placing them under the Ramsar Convention would be important to prevent global extinction of the species.

Although the population of mangrove horseshoe crabs at Kranji has long been known to exist, this is the first study to collect data on the abundance or population density of Carcinoscorpius rotundicauda in the area. These data will provide useful baseline information with which to monitor the size of the population over the coming years. The paucity of recent density and abundance figures has led to the IUCN classification for C. rotundicauda as 'data deficient'; our study is a first step in addressing this data gap. Without regular and reliable density data it is impossible to gauge the effects of threats to the species, determine conservation strategies, or persuade governments that action is needed.

Acknowledgements. Nature Society (Singapore) wishes to thank Caterpillar Foundation for their generous funding to conduct the present study. We also extend our thanks to the many individual NSS members who gave of their time and effort to help with the horseshoe crab searches. In addition, many thanks to the volunteers from the following schools and institutions who helped with the searches: the National Institute of Education (NIE), the International School of Singapore (ISS), Bukit View Secondary School and Nanyang Junior College. In addition, Dr. P. Todd, of the National University of Singapore (NUS) helped with the design at the start of the project. Thanks also go to Umoe Schat-Harding for the use of their facilities near the study site at Kranji. 


\section{LITERATURE CITED}

Almendral MA, Schoppe S (2005) Population structure of Tachypleus tridentatus (Chelicerata: Merostomata) at a nursery beach in Puerto Princesa City, Palawan, Philippines. J Nat Hist 39:2319-2329

Carmichael RH, Rutecki D, Valiela I (2003) Abundance and population structure of the Atlantic horseshoe crab Limulus polyphemus in Pleasant Bay, Cape Cod. Mar Ecol Prog Ser 246:225-239

Cartwright-Taylor L (2008) Studies on the abundance, population density and structure and breeding patterns of the mangrove horseshoe crab, Carcinoscorpius rotundicauda, at Mandai mud-flats in Singapore. MSc dissertation, Napier University, Edinburgh

Cartwright-Taylor L, Lee J, Hsu CC (2009) Population structure and breeding pattern of the mangrove horseshoe crab Carcinoscorpius rotundicauda in Singapore. Aquat Biol 8: 61-69

Chalmers N, Parker P (1989) The OU project guide: fieldwork and statistics for ecological projects, 2nd edn. No. 9, Field Studies Council, Open University, Shrewsbury

Chatterji A (1999) New record of the sympatric distribution of two Asian species of the horseshoe crab. Curr Sci 77(6): 746-747. Available at www.ias.ac.in/currsci/sep25/articles 14.htm, accessed on 23 September 2008

Chatterji A, Abidi SAHJ (1993) The Indian horseshoe crab: a living fossil. J Indian Ocean Stud 1:43-48

Chatterji A, Vijayakumar R, Parulekar AH (1992) Spawning migration of the horseshoe crab, Tachypleus gigas (Müller), in relation to lunar cycle. Asian Fish Sci 5:123-128

Chen CP, Yeh HY, Lin PF (2004) Conservation of the horseshoe crab at Kinmen, Taiwan: strategies and practices. Biodivers Conserv 13:1889-1904

Chiu HMC, Morton B (1999) The distribution of horseshoe crabs (Tachypleus tridentatus and Carcinoscorpius rotundicauda) in Hong Kong. Asian Mar Biol 16:185-196

Chiu HMC, Morton B (2003) The status of horseshoe crabs in Hong Kong. In: Morton B (ed) Perspectives on marine environmental change in Hong Kong and southern China. Proceedings of the Hong Kong workshops reunion conference on perspectives on marine environmental change in Hong Kong and southern China (1977-2001). Hong Kong University Press, Hong Kong, p 743-758

Christianus A, Saad CR (2007) Horseshoe crabs in Malaysia and the world. FishMail 16:8-9

Davidson GWH, Ng PKL, Ho HC (2008) The Singapore Red Data Book: threatened plants and animals of Singapore. The Nature Society (Singapore), Singapore

Ding JL, Tan KC, Thangamani S, Kusuma N and others (2005) Spatial and temporal co-ordination of expression of immune response genes during Pseudomonas infection of horseshoe crab. Genes Immun 6:557-574

Editorial responsibility: Hans Heinrich Janssen, Oldendorf/Luhe, Germany
Earle SA (1991) Sharks, squids, and horseshoe crabsThe significance of marine biodiversity. Bioscience 41: 506-509

> Hu M, Wang Y, Chen Y, Cheung SG, Shin PKS, Li Q (2009) Summer distribution and abundance of juvenile Chinese horseshoe crabs Tachypleus tridentatus along an intertidal zone in southern China. Aquat Biol 7:107-112

Itow T (1993) Crisis in the Seto Inland Sea: the decimation of the horseshoe crab. EMECS Newsl 3:10-11

IUCN (International Union for Conservation of Nature) (2010) Red List of threatened species. Available at: www.iucnredlist.org (accessed on 24 February 2010)

> Lee CN, Morton B (2005) Experimentally derived estimates of growth by juvenile Tachypleus tridentatus and Carcinoscorpius rotundicauda (Xiphosura) from nursery beaches in Hong Kong. J Exp Mar Biol Ecol 318:39-49

Mikkelsen T (1988) The secret in the blue blood. Science Press, Beijing

Mishra JK (2009) Horseshoe crabs, their eco-biological status along the north-east coast of India and the necessity for ecological conservation. In: Tanacredi JT, Botton ML, Smith DR, Earle SA (eds) Biology and conservation of horseshoe crabs. Springer Science and Business Media, Heidelberg, p 89-96

Morton B (1999) On turtles, dolphins and, now, Asia's horseshoe crabs. Mar Pollut Bull 38:845-846

Ng PKL, Sivasothi N (2002) A guide to the mangroves of Singapore. I. The ecosystem and plant diversity, 2nd edn. BP Guide to Nature Series, Singapore Science Centre, Singapore

Patti B (2008) Horseshoe crabs galloping towards extinction. Available at: www.marinenews.com (accessed on 29 June 2008)

R Development Core Team (2009) R: a language and environment for statistical computing. R Foundation for Statistical Computing, Vienna. Available at: www.R-project.org

Sekiguchi K (1988) Biology of horseshoe crabs. Science House, Tokyo

Sgrillo RB (2009) Tools for Google Earth: GE-Path Version 1.4.4. Available at: http://sgrillo.net/googleearth/index. htm (accessed on 28 October 2010)

Shin P, Li HY, Cheung SG (2009) Horseshoe crabs in Hong Kong: current population status and human exploitation. In: Tanacredi JT, Botton ML, Smith DR, Earle SA (eds) Biology and conservation of horseshoe crabs. Springer Science and Business Media, Heidelberg, p 347-360

Smith DR, Pooler PS, Swan BL, Michels SF, Hall WR, Himchak PJ, Millard MJ (2002) Spatial and temporal distribution of horseshoe crab (Limulus polyphemus) spawning in Delaware Bay: implications for monitoring. Estuaries 25:115-125

Yee ATK, Ang WF, Teo S, Liew CS, Tan HTW (2010) The present extent of mangrove forests in Singapore. Nature Singapore 3:139-145

Submitted: July 7, 2010; Accepted: April 5, 2011

Proofs received from author(s): July 29, 2011 